\title{
CLINICAL RESULTS OF CORONARY ARTERY BYPASS GRAFTING WITH USE OF THE INTERNAL THORACIC ARTERY UNDER LOW FREE FLOW CONDITIONS
}

\author{
Mitsumasa Hata, MD \\ Motomi Shiono, $\mathrm{MD}^{\mathrm{a}}$ \\ Yukihiko Orime, $\mathrm{MD}^{\mathrm{a}}$ \\ Shinya Yagi, MD \\ Tomonori Yamamoto, $\mathrm{MD}^{\mathrm{a}}$ \\ Haruhiko Okumura, $\mathrm{MD}^{\mathrm{a}}$ \\ Shun-ichi Kimura, MD \\ Akira Sezai, MD \\ Satoshi Kashiwazaki, MD \\ Shinsuke Choh, MD \\ Nanao Negishi, MD \\ Yukiyasu Sezai, $\mathrm{MD}^{\mathrm{a}}$ \\ Eise Yokoyama, $\mathrm{PhD}^{\mathrm{b}}$ \\ Hiroaki Hata, MD
}

Objective: Even when left internal thoracic artery flow is very low, we have used the artery for grafting without any further maneuvers. In this study, we investigated the clinical results of coronary bypass surgery using the left internal thoracic artery with low free flow. Methods: A total of 163 patients were divided into 2 groups: group $L(n=43)$ had free flow of $20 \mathrm{~mL} / \mathrm{min}$ or less and group $H(n=120)$ had free flow of more than $20 \mathrm{~mL} / \mathrm{min}$. We performed a comparative study on the basis of coronary angiography and pulsed Doppler echocardiography. Furthermore, 12 months' postoperative graft angiography was carried out in 11 patients from group L. Results: No patient had low output syndrome or perioperative myocardial infarction. One month after the operation, 3 cases of graft occlusion and 9 cases of the "string sign" were identified in group $H$. However, group $L$ had no graft occlusion and only 1 case of the "string sign." The 1-month postoperative Doppler echocardiographic study showed no significant differences in the diastolic fraction of velocity time integrals and the diastolic/systolic peak velocity ratio of the grafts. In the 11 patients undergoing angiography after 1 year, graft patency was excellent. Moreover, the graft diameter was significantly larger than it was 1 month after the operation. Conclusion: These results suggest that the left internal thoracic artery can be used for coronary artery bypass grafting even when the flow is less than 20 mL/min. (J Thorac Cardiovasc Surg 2000;119:125-9)
C urrently, the internal thoracic artery (ITA) is generally used to provide grafts having long-term patency in coronary artery bypass grafting (CABG). In particular, use of the left internal thoracic artery (LITA) graft to revascularize the left anterior descending coronary artery (LAD) has significantly improved the longterm results of CABG. ${ }^{1}$ It is believed that use of the LITA should be avoided when the free flow is too low. However, the most suitable conditions for ITA grafts in CABG have not yet been determined, and detailed

From the Second Department of Surgery and Public Health, ${ }^{\mathrm{b}}$ Nihon University School of Medicine, Tokyo, and The Department of Cardiovascular Surgery, ${ }^{\mathrm{c}}$ Okaya Enrei Hospital, Nagano, Japan.

Part of this study was presented at the seventieth meeting of the American Heart Association, Orlando, Fla, 1997.

Received for publication May 28, 1999; revisions requested Aug 24, 1999; revisions received Sept 29, 1999; accepted for publication Oct $5,1999$.

Address for reprints: Mitsumasa Hata, MD, 30-1 Oyaguchi Kamimachi, Itabashi-ku, Tokyo 173-8610, Japan (E-mail: mihata@med.nihon-u.ac.jp).

Copyright $\odot 2000$ by Mosby, Inc.

$0022-5223 / 2000 \$ 12.00+0 \quad \mathbf{1 2 / 1 / 1 0 3 4 6 0}$ investigations of ITA free flow have not been reported. It is generally accepted that the ITA is suitable for CABG when the free flow rate is more than 40 to 80 $\mathrm{mL} / \mathrm{min},{ }^{2,3}$ and Mills and colleagues recommend 120 $\mathrm{mL}$ of free flow as the minimum for use of the ITA grafts. ${ }^{4}$ From a variety of reports in the world literature, it seems that the ITA is used only when the free flow is more than $20 \mathrm{~mL} / \mathrm{min}$ after relief of spasm. ${ }^{5}$ However, ITA flow may increase in proportion to the myocardial blood demand after grafting if there is no mechanical damage to the vessel during mobilization. Therefore, even when ITA flow is very low, we consider that its use without any further intraluminal maneuvers provides the best graft. The aim of this study is to investigate the clinical results of CABG with the use of a LITA with low free flow and to evaluate the postoperative hemodynamic status of low free flow grafts by means of transthoracic pulsed Doppler echocardiography.

\section{Patients and methods}

Between December 1997 and December 1998, 180 patients underwent $\mathrm{CABG}$ at our hospital and an associated institution. In 163 of them, the LITA was anastomosed to the LAD. 
Table I. Patient profile

\begin{tabular}{lccc}
\hline & Group H & Group $L$ & P value \\
\hline Age (y) & $62.4 \pm 7.5$ & $61.6 \pm 6.7$ & $<.02$ \\
Sex (No. of patients) & & & $<.02$ \\
$\quad$ Male & 104 & 38 & \\
$\quad$ Female & 16 & 5 & \\
Smoking (\%) & 65.4 & 67.0 & $<.02$ \\
HT (\%) & 76.0 & 68.0 & $<.02$ \\
HL (\%) & 35.7 & 38.0 & $<.02$ \\
DM (\%) & 33.1 & 37.0 & $<.02$ \\
CAD (cases) & & & $<.02$ \\
$\quad$ Two-vessel disease & 24 & 8 & \\
$\quad$ Three-vessel disease & 96 & 35 & \\
MI (\%) & 72.6 & 80.2 & $<.02$ \\
\hline
\end{tabular}

$M$, Male; $F$, female; $H T$, hypertension; $H L$, hyperlipidemia; $D M$, diabetes mellitus; $C A D$, coronary artery disease; $M I$, myocardial infarction.

The LITA was dissected with a pedicle by means of electrocauterization and a protective gauze pad. Titanium Hemoclip clamps (Weck Closure Systems, Research Triangle Park, NC) were used to clamp the LITA branches. After complete mobilization, we cut the LITA just proximal to its bifurcation and confirmed pulsatile blood flow from the cut end. The distal cut end was then closed with a Hemoclip clamp. The mobilized LITA was then covered with $0.2 \%$ papaverine-soaked gauze. However, papaverine administration and balloon dilation of the LITA were not used. Flow was measured by allowing the cut end of the LITA to bleed into a graduated cylinder for 15 seconds. If pulsatile blood flow was detected, even though the LITA flow was very low, we anastomosed the LITA to the LAD without any further maneuvers. Cardiopulmonary bypass (CPB) was established from the right atrium to the ascending aorta. As soon as the aortic crossclamp was placed, St Thomas' Hospital cardioplegic solution $(30 \mathrm{~mL} / \mathrm{kg})$ was administered through the aortic root cannula. Bypass was performed at the mid portion of the LAD with an 8-0 polypropylene nonabsorbable suture. Side branches of the LITA had been ligated. Saphenous vein grafts were used for all diseased vessels except for the LAD. The proximal anastomosis between the saphenous vein graft and the ascending aorta was performed under partial aortic clamping. The 163 patients were divided into 2 groups: (1) group L, consisting of 43 patients in whom the LITA free flow was $20 \mathrm{~mL} / \mathrm{min}$ or less; (2) group $\mathrm{H}$, consisting of 120 patients in whom it was more than $20 \mathrm{~mL} / \mathrm{min}$. We performed a comparative study between the 2 groups on the basis of 1 month postoperative coronary angiographic findings. We also evaluated the postoperative hemodynamic status of the low free flow LITA cases by means of transthoracic pulsed Doppler echocardiography. Color Doppler echocardiographic examination was performed from the anterior chest wall at almost the same time as postoperative graft angiography with an Acuson Sequoia C256 machine (Acuson Corporation, Mountain View, Calif) equipped with a 7-MHZ transducer. All patients took nitroglycerin tablets just before the Doppler
Table II. LITA diameter on preoperative angiography, graft number, and LITA free flow

\begin{tabular}{lccc}
\hline & Group H & Group L & P value \\
\hline LITA diameter (mm) & $1.8 \pm 0.9$ & $1.9 \pm 0.6$ & $<.02$ \\
Bypass No. (branches) & $2.8 \pm 0.7$ & $2.7 \pm 0.8$ & $<.02$ \\
Free flow (mL/min) & $51.0 \pm 15.4$ & $15.0 \pm 5.0$ & .0007 \\
\hline
\end{tabular}

study. The diastolic and systolic peak velocity ratio (D/S ratio) and diastolic fraction (DF) of the velocity time integral were measured with on-line calipers and averaged over 3 cardiac cycles. All echocardiographic examinations and measurements were performed by the same physician.

Statistical analysis: Mean and standard deviation for the metric data. Statistical differences between the groups tested were analyzed with the $\chi^{2}$ test, Student $t$ test, and unpaired $t$ test. Significance was defined as a $P$ value of less than .02 .

\section{Results}

All patients were easily weaned from CPB. No patient had low output syndrome or perioperative myocardial infarction. There were no significant differences in age, sex, coronary risk factors, diseased vessels, and preoperative myocardial infarction between the 2 groups (Table I), nor were there significant difference in body surface area between the 2 groups. We evaluated the preoperative native LAD flow area on the basis of the classification of Pujardas. ${ }^{6}$ In group $\mathrm{H}$, there were 31 patients of type L, 66 of type M, and 23 of type S. In group L, there were 9 patients of type L, 25 of type $M$, and 9 of type $S$. No significant difference was identified between the 2 groups. Preoperative native LAD stenosis, the ejection fraction, the left ventricular end-diastolic pressure, the aortic crossclamping time, the CPB time, and the systolic aortic pressure during evaluation of the free flow all showed no significant differences. LITA diameter was evaluated just proximal to its bifurcation by preoperative coronary angiography. In all patients, no atherosclerotic findings were evident in either the left subclavian artery or the proximal LITA. In group $\mathrm{H}$, the diameter was $1.8 \pm 0.9$ $\mathrm{mm}$ and in group $\mathrm{L}$, it was $1.9 \pm 0.6 \mathrm{~mm}$; thus there was no significant difference (Table II). Likewise, the number of arteries bypassed was not significantly different (Table II). LITA free flow ranged from 24 to 86 $\mathrm{mL} / \mathrm{min}$ in group $\mathrm{H}$, with an average of $51.0 \mathrm{~mL} / \mathrm{min}$, whereas it ranged from 5 to $20 \mathrm{~mL} / \mathrm{min}$ in group L, with an average of $15.0 \mathrm{~mL} / \mathrm{min}$ (Table II). In the 1month postoperative angiographic study there were 3 cases of LITA graft occlusion in group $\mathrm{H}$, and distal narrowing of the LITA graft, the so-called "string 
sign," was seen in 9 cases (Table III). In group L, the string sign was identified in 1 case and LITA occlusion in 1 case. The proportion of satisfactory results from early graft patency was $97.5 \%$ in group $\mathrm{H}$ and $97.6 \%$ in group L (Table III).

The LITA was adequately identified and good quality Doppler waveforms were obtained in 148 (98.7\%) of the 150 patients with a patent LITA. The Doppler waveform in the distal portion of the grafted LITA obtained by the transthoracic approach had a biphasic pattern with a higher mid-diastolic component and a lower antegrade component at end-systole. In the patients with graft occlusion or the string sign, the distal portion of the LITA was not detected. In the distal portion of the grafted LITA, D/S and DF did not differ between groups $\mathrm{H}$ and $\mathrm{L}(\mathrm{D} / \mathrm{S}: 1.62 \pm 0.46$ vs $1.66 \pm$ 0.31 ; DF: $0.71 \pm 0.16$ vs $0.74 \pm 0.38$ ).

One-year postoperative graft angiography was carried out in 11 group L patients. Their courses had been uneventful for 1 year, and LITA graft patency was excellent. In fact, the graft diameter at 1-year postoperative angiography $(2.1 \pm 0.4 \mathrm{~mm})$ was significantly larger than that 1 month after the operation $(1.7 \pm 0.5$ $\mathrm{mm})$. In 23 patients in group $\mathrm{H}$, the LITA diameter (2.2 \pm 0.6 ) was also enlarged compared with that 1 month after the operation $(1.7 \pm 0.3 \mathrm{~mm})$. There were no significant differences in graft diameter between groups $\mathrm{L}$ and $\mathrm{H} 1$ year after the operation.

\section{Discussion}

What is the cause of low ITA free flow during CABG? The main causes are considered to be temporary spasm or mechanical damage inflicted by surgical maneuvers. When the mobilized ITA free flow is very low, several surgeons recommend several methods to increase the free flow, such as papaverine administration, metallic cannula insertion, and intraluminal balloon dilation. ${ }^{4,7}$ When the free flow is significantly increased by intraluminal papaverine administration, the cause of low free flow is regarded as temporary vasospasm. In fact, the ITA is used for grafting only when the free flow is more than $20 \mathrm{~mL} / \mathrm{min}$ after relief of spasm..$^{5}$ However, several investigators have suggested that the ITA intima may deteriorate as the result of papaverine injection. ${ }^{8,9}$ Balloon dilation is considered even more dangerous. We agree that those intraluminal maneuvers may impair the ITA quality. We previously inserted a Parsonnet probe into a low free flow LITA in 1 patient. Although flow was slightly increased, we decided not to use the vessel. We resected the whole LITA and evaluated it microscopically, discovering intimal dissection along the entire vessel.
Table III. Early postoperative graft angiography

\begin{tabular}{lccc}
\hline & Group H & Group L & P value \\
\hline Graft occlusion & $3(2.5 \%)$ & $1(2.3 \%)$ & $<.02$ \\
String sign & $9(7.5 \%)$ & $1(2.3 \%)$ & $<.02$ \\
Patency rate & $97.5 \%$ & $97.6 \%$ & $<.02$ \\
\hline
\end{tabular}

Thus it is virtually impossible to determine the actual cause of blood flow reduction without pathologic study of the completely mobilized artery. However, pulsatile blood flow is evidence of blood transmission through the ITA. Intraluminal papaverine preparation of the ITA is one of the methods used to distinguish low flow caused by technical error or vasospasm. However, papaverine has an acidic $\mathrm{pH}$ (3-4.5), and although this is partially neutralized with the addition of normal saline solution ( $\mathrm{pH}$ 5.2), there is still reasonable concern that arterial wall and endothelial damage may result, compromising long-term patency. ${ }^{10} \mathrm{We}$ contend that the intraluminal maneuvers used on low free flow ITAs to increase the flow may actually result in the string sign or late occlusion.

After complete mobilization, we evaluate LITA free flow just proximal to its bifurcation. However, the more proximal portion of LITA is used for anastomosis to the LAD. He and colleagues ${ }^{11}$ reported that variations in reactivity are shown along the full length of the human ITA. Furthermore, they insist that the distal portion of the ITA is most sensitive. Therefore the portion of the LITA in which we assessed free flow may be more easily affected by vasospasm. Whether the mobilized LITA is acceptable or not according to the free flow in the distal portion cannot be determined until an appropriate length of graft is chosen to anastomose it to the LAD. A high blood flow from the LITA appears during CPB because of pump flow. However, blood pulsatility cannot be confirmed in this situation. Arterial conduits may develop spasm at harvest. This condition is variable in its severity and is not always effectively treated with topical papaverine. However, even though the free flow is low due to spasm, one can be sure that if blood pulsatility from the cut end was maintained there was no mechanical damage of the intima. Thus we believe it is important to recognize pulsatility of flow as an indicator of absence of mechanical damage. Tector ${ }^{12}$ also emphasized the importance of testing the flow and pulse in the spatulated distal end of the LITA before going on CPB. These studies ${ }^{11,12}$ and ours show that LITA low free flow was caused by temporary spasm resulting from harvest. 
The ITA is a so-called "living conduit," in which the diameter may increase in the late postoperative period. Kitamura and colleagues ${ }^{13}$ reported that ITA flow increased in response to patient growth after CABG for Kawasaki disease. Akasaka and colleagues ${ }^{14}$ also reported that ITA flow capacity increased in the late postoperative period because of an increase in ITA diameter. Furthermore, Gurne and colleagues ${ }^{15}$ described that an increase in myocardial blood flow induced by pacing resulted in vasodilation of the ITA in the late postoperative periods. We also consider that ITA flow may increase in proportion to the myocardial blood demand if there is no damage during mobilization. In this series, enlargement of graft diameter was seen after 1 year in 11 patients with low free flow. It is reported that if the endothelium is preserved during surgical preparation, the ITA has a potent endogenous nitrate system that can help prevent vasospasm, thrombus formation, and graft occlusion. ${ }^{16}$ Therefore, even when ITA flow is very low, we believe that anastomosis without any further maneuvers is the best approach in terms of quality.

In this series, 9 patients (7.5\%) had a string sign in group $\mathrm{H}$. This is a rather high percentage. One cause of string sign is believed to be the competition of native blood flow with LITA blood flow. Seki and colleagues ${ }^{17}$ reported that LITA string sign was observed in $9(6.1 \%)$ of 147 patients and in all of those patients whose native LAD flow was well preserved. Six of our 9 patients with string signs had about $50 \%$ to $75 \%$ narrowing of the native LAD. Thus their LAD flow might also be preserved. Seki and associates ${ }^{17}$ also showed a strong inverse correlation between $25 \%$ and $50 \%$ stenosis of native LAD and LITA diameter. With these results, we consider that a LITA anastomosed to the LAD with minimal stenosis caused the string sign in the early postoperative period.

In our hospital, we used the simplest method of LITA mobilization and covered the vessel only with papaverine-soaked gauze. In group L, even though mobilized LITA free flow was very low, there were no cases of hemodynamic instability or perioperative myocardial infarction. In comparisons of the LAD flow area, there were no significant differences between the groups. Furthermore, the proportions of satisfactory results from early graft patency were about $97 \%$. However, several investigators have reported a discrepancy between angiographic and pulsed Doppler findings of the LITA. ${ }^{18}$ The D/S ratio is sometimes very low on echocardiography, despite excellent postoperative graft patency on angiography. Furutani and colleagues ${ }^{19}$ reported that the LITA D/S ratio and DF were low in patients with minimal stenosis of the native LAD. These findings indicate competition of native blood flow with LITA flow, which may cause the ITA string sign in the late postoperative period. In assessment of the postoperative LITA hemodynamic status, it is more important to assess the blood flow waveform than its flow rate.

In this study, we assessed the early postoperative hemodynamic status of the ITA by pulsed Doppler echocardiography. Several recent reports have suggested that coronary flow reserve measurement by transthoracic Doppler echocardiography is useful for assessment of significant LAD stenosis. ${ }^{20}$ Furthermore, transthoracic pulsed Doppler echocardiography is an effective and noninvasive method of assessing postoperative LITA graft function. ${ }^{21}$ In our series, stress test and myocardial scintigraphy were not used to evaluate the coronary flow reserve. We conclude that it is possible to use a low free flow ITA because of the stable postoperative course and excellent ITA Doppler waveform in group L. In the distal LITA, the postoperative early blood flow velocity waveform in group L was excellent despite low free flow during the procedure. Furthermore, the D/S ratio and DF were no different from those in group H. Thus LITAs with a low free flow increase postoperatively not only angiographically but also on Doppler findings.

\section{Conclusion}

The ITA can be used for CABG even when the free flow is less than $20 \mathrm{~mL} / \mathrm{min}$, because the vessel increases in diameter in response to myocardial blood demand.

\section{REFERENCES}

1. Lytle BW, Loop FD, Cosgrove DM, Ratliff NB, Easley K, Taylor PC. Long-term (5 to 12 years) serial studies of internal mammary artery and saphenous vein coronary bypass grafts. J Thorac Cardiovasc Surg 1985;89:248-58.

2. Tyras DH, Barner HB, Kaiser GC, Codd JE, Pennington DG, Willman VL. Bypass grafts to the left anterior descending coronary artery: saphenous vein versus internal mammary artery. J Thorac Cardiovasc Surg 1980;80:327-33.

3. Green GE. Internal mammary coronary artery anastomosis for myocardial ischemia. In: Sabiston DC Jr, Spencer FC, editors. Gibbon's surgery of the chest, vol II, 4th ed. Philadelphia: WB Saunders; 1983. p. 1082-7.

4. Mills NL, Bringaze WL. Preparation of the internal mammary artery graft: Which is the best method? J Thorac Cardiovasc Surg 1989;98:73-9.

5. Yasuura K, Okamoto H, Matsuura A, Akita T, Sawazaki M, Abe $\mathrm{T}$, et al. The significance of internal thoracic artery-left anterior descending coronary artery bypass grafting in postoperative angiographic studies-with reference to indication of ITA and factors of string sign. J Jpn Assoc Thorac Surg 1991;39:14-20. 
6. Pujardas G. Normal patterns of coronary arteries. In: Pujardas G, editor. Coronary angiography. New York: McGraw-Hill; 1980. p. 98-100.

7. Gaudiani VA, Bush WS, Chin AK, Ayres LJ, Fogarty TJ. An improved technique for the internal mammary artery-coronary bypass graft procedure. J Card Surg 1988;3:467-73.

8. Dregelid E, Heldal K, Resch F, Stangeland L, Breivik K, Svendsen E. Dilation of the internal mammary artery by external and internal papaverine application. J Thorac Cardiovasc Surg 1995;110:697-703.

9. Barner HB, Fischer VW, Beaudet L. Effects of dilation with a balloon catheter on the endothelium of the internal thoracic artery. J Thorac Cardiovasc Surg 1992;103:375-80.

10. Nashef SAM, Angelini GD. Preparation of the internal mammary artery. Br J Hosp Med 1990;45:339-42.

11. He GW, Acuff TE, Yang CQ, Ryan WH, Mack MJ. Middle and proximal section of the human internal mammary artery are not "passive conduits." J Thorac Cardiovasc Surg 1994;108:741-6.

12. Tector AJ. Creative use of arterial conduits and current results. In: Emery RW, editor. Techniques for minimally invasive direct coronary artery bypass (MIDCAB) surgery. Philadelphia: Hanley \& Belfus; 1997. p. 9-15.

13. Kitamura S, Ooyama A, Kawachi K, Kobayashi H, Morita R, Nishii $\mathrm{T}$, et al. Arterial grafts for coronary artery bypass surgery: internal mammary artery grafts as viable conduits. J Jpn Coll Angiol 1987;27:559-65.

14. Akasaka T, Yoshikawa J, Yoshida K, Maeda K, Hozumi T, Nasu $\mathrm{M}$, et al. Flow capacity of internal mammary artery grafts: early restriction and later improvement assessed by Doppler guide wire-comparison with saphenous vein grafts. J Am Coll Cardiol 1995;25:640-7.
15. Gurne O, Chenu P, Polidori C, Louagie Y, Buche M, Haxhe JP, et al. Functional evaluation of internal mammary artery bypass grafts in early and late postoperative periods. J Am Coll Cardiol 1995;25:1120-8.

16. Carrier M. Alternative arterial conduits and surgical approaches: endovascular biology. In: Emery RW, editor. Techniques for minimally invasive direct coronary artery bypass (MIDCAB) surgery. Philadelphia: Hanley \& Belfus; 1997. p. 17-22.

17. Seki T, Kitamura S, Kawachi K, Morita R, Kawata T, Mizuguchi $\mathrm{K}$, et al. A quantitative study of postoperative luminal narrowing of the internal thoracic artery graft in coronary artery bypass surgery. J Thorac Cardiovasc Surg 1992;104:1532-8.

18. Pezzano A, Fusco R, Child M, Riccobono S, Milazzo A, Recalcati F, et al. Assessment of left internal mammary artery grafts using dipyridamole Doppler echocardiography. Am J Cardiol 1997;80:1603-6.

19. Furutani Y, Takahashi T, Imagawa H, Taniguchi K, Kadoba K, Matsuda $\mathrm{H}$. Noninvasive hemodynamic assessment of internal thoracic artery grafts using duplex echocardiography from supraclavicular fossa - a comparison with Doppler catheter method. J Jpn Assoc Thorac Surg 1997;45:1803-9.

20. Hozumi T, Yoshida K, Ogata Y, Akasaka T, Asami Y, Takagi T, et al. Noninvasive assessment of significant left anterior descending coronary artery stenosis by coronary flow velocity reserve with transthoracic color Doppler echocardiography. Circulation 1997; 97:1557-62.

21. Süngün M, Duran E, Cebeci BS, Us MH, Saba D, Saygin G. The assessment of internal mammary artery grafts by color Doppler in coronary artery surgery. J Cardiovasc Surg 1998;39: 75-8. 